University of Wollongong

Research Online

Faculty of Social Sciences - Papers (Archive) Faculty of Arts, Social Sciences \& Humanities

2015

Designing a digital teaching resource to explain phases of the moon: a case study of preservice elementary teachers making a slowmation

Wendy S. Nielsen

University of Wollongong, wnielsen@uow.edu.au

Garry F. Hoban

University of Wollongong, garry_hoban@uow.edu.au

Follow this and additional works at: https://ro.uow.edu.au/sspapers

Part of the Education Commons, and the Social and Behavioral Sciences Commons

Research Online is the open access institutional repository for the University of Wollongong. For further information contact the UOW Library: research-pubs@uow.edu.au 


\title{
Designing a digital teaching resource to explain phases of the moon: a case study of preservice elementary teachers making a slowmation
}

\begin{abstract}
This research studied a group of three preservice elementary teachers creating a narrated stop-motion animation (Slowmation) from start to finish in 3 hours to explain the challenging concept of "phases of the moon" to elementary school children. The research questions investigated the preservice teachers' learning before and after the construction as well as how the preservice teachers designed the slowmation as a teaching resource. Data collection involved individual interviews immediately before and after the construction in conjunction with analysis of video and audio data collected during the construction process. Before the animation construction, the participants had little understanding of the causes of moon phases and one held an alternative conception. After creating the slowmation all three preservice teachers demonstrated more "elements" of the concept and appeared to resolve an alternative conception. There are two findings from this research: (i) creating a slowmation enabled the preservice teachers to develop more elements to contribute to their understanding of moon phases; (ii) the design of the slowmation was based on breaking the concept into a sequence of sub-concepts that were represented digitally. Designing a digital teaching resource such as a slowmation to explain a concept involves preservice teachers breaking a concept down into coherent parts or "chunks" and representing the concept in multiple ways. This can be done within a science method class and is also a good way for the them to negotiate meanings about a difficult concept.
\end{abstract}

\section{Keywords}

slowmation, digital, making, designing, preservice, study, case, moon, phases, explain, resource, teaching, elementary, teachers

\section{Disciplines}

Education | Social and Behavioral Sciences

\section{Publication Details}

Nielsen, W. \& Hoban, G. (2015). Designing a digital teaching resource to explain phases of the moon: a case study of preservice elementary teachers making a slowmation. Journal of Research in Science Teaching, 52 (9), 1207-1233. 
Running Head: PRESERVICE TEACHERS DESIGNING A DIGITAL TEACHING RESOURCE

Designing a Digital Teaching Resource to Explain Phases of the Moon: A Case Study of Preservice Elementary Teachers Making a Slowmation

Wendy Nielsen and Garry Hoban

University of Wollongong

Correspondence should be addressed to Wendy Nielsen, School of Education, University of Wollongong, New South Wales, Australia 2522

Contact:wnielsen@uow.edu.au 


\begin{abstract}
This research studied a group of three preservice elementary teachers creating a narrated stop-motion animation (Slowmation) from start to finish in three hours to explain the challenging concept of "phases of the moon" to elementary school children. The research questions investigated the preservice teachers' learning before and after the construction as well as how the preservice teachers designed the slowmation as a teaching resource. Data collection involved individual interviews immediately before and after the construction in conjunction with analysis of video and audio data collected during the construction process. Before the animation construction, the participants had little understanding of the causes of moon phases and one held an alternative conception. After creating the slowmation all three preservice teachers demonstrated more "elements" of the concept and appeared to resolve an alternative conception. There are two findings from this research: (i) creating a slowmation enabled the preservice teachers to develop more elements to contribute to their understanding of moon phases; (ii) the design of the slowmation was based on breaking the concept into a sequence of sub-concepts that were represented digitally. Designing a digital teaching resource such as a slowmation to explain a concept involves preservice teachers breaking a concept down into coherent parts or "chunks" and representing the concept in multiple ways. This can be done within a science method class and is also a good way for the them to negotiate meanings about a difficult concept.
\end{abstract}

Keywords: Slowmation; technology; animation; semiotics; multimodal representation; moon phases; teaching resource 


\section{Designing a Digital Teaching Resource to Explain Phases of the Moon: A Case Study of Preservice Elementary Teachers Making a Slowmation}

Encouraging preservice elementary teachers to discuss and explain science knowledge during their science method courses is an important way for them to engage with content and develop insights into their own learning of science (Davis, Petish, \& Smithey, 2006; National Research Council, 2012; Tytler, 2008). In addition to verbally explaining science, preservice teachers can use their own technology tools to create multimodal products as explanatory resources, the creation of which involves additional layers of interpreting and representing concepts (Prain \& Waldrip, 2006; Yore \& Hand, 2010). Explaining content through digital representation is a form of learner engagement, and using technology helps preservice teachers to develop digital literacy skills and other $21^{\text {st }}$ century skills such as creativity, problem solving, communication and collaboration (National Research Council, 2012).

Research in the cognitive sciences has shown that getting students to explain concepts to other students is valuable for learning because they first have to understand the content as a prerequisite to generating an explanation. Chi and colleagues called this the "self-explanation effect” (Chi, Bassok, Lewis, Reimann, \& Glaser, 1989; Chi, de Leeuw, \& Chiu, 1994). In the experimental studies from Chi's team, a group of participants was asked to explain math problems to themselves and others whilst being compared to other groups who did not do this self-explaining. Results showed that the self-explainers outperformed the non-explainers in various tests to assess understanding and transfer of the knowledge. We link this form of verbal explanation to teaching expectancy, where learning may be enhanced when students are encouraged to teach others (Fiorella \& Mayer, 2014; Hiller, Deichman, \& Pirkle, 1973). When education students studying calculus were asked to explain worked examples to a third person, they were more engaged in studying the worked examples (Renkl, 1995). Renkl also noted learning gains when students had sufficient time to construct a good representation of the problem suggesting a link between learning and preparing material for teaching that includes generating representations.

Research in the cognitive sciences offers grounding for why creating a verbal explanation as a teaching resource helps understanding. Developing an explanation of a concept encourages additional engagement with the content because the expectancy to teach produces changes in how information is processed and represented. This includes organizing the study material, which enhances memory recall of the main points (Nestojko, Bui, Kornell, \& Bjork, 2014). Nestojko et al. adopted an experimental approach to compare learning when teaching expectancy or test expectancy were goals for learning. In summary the researchers found that "expecting to teach appears to encourage effective learning strategies such as seeking out key points and organizing information into a coherent structure” (Nestojko et al., 2014, p. 1047). While the learners in the research were not preservice teachers, the study offers a possible reason for why an expectancy to teach supports learning: the students focus on information processing in developing an explanation because the structure of the concept must be broken down and organised in a sequence in order to create a teaching resource for others. This supports the claim by Jonassen, Myers and McKillop (1996) that "the people who learn the most from instructional materials are the designers.... we have all stated at one time or another that the quickest way to learn about subject matter is to have to teach (design) it" (p. 95).

Furthermore, designing a digital teaching resource creates additional engagement for students because they not only need to understand a concept in order to explain it and organise it in a sequence, but they also represent it using multiple modes of communication. One way for preservice teachers to create a digital teaching resource is to use their own 
technology (digital still camera or cell phone and computer) to design a narrated stop-motion animation to explain science concepts (Hoban, 2007, 2009). "Slowmation" (abbreviated from "Slow Animation") is a simplified way for preservice teachers to make a narrated stop-motion animation that plays slowly at 2 frames per second providing a slow moving image that the creators narrate to explain science (Hoban, 2005). Preservice teachers can learn the process in 1-2 hours and create models out of everyday materials such as plasticine, cardboard or paper or use existing plastic models and take digital still photos as the models are moved manually. Slowmation is a visualization technique involving model-making, which is an important part of science learning (Gilbert, 2007; Phillips, Norris, \& Macnab, 2010). Whilst there have been studies on the process that preservice teachers use in constructing a slowmation (Hoban \& Nielsen, 2010), the type and sequences of representations in construction (Hoban, Loughran, \& Nielsen, 2011) and the nature of learning (Hoban \& Nielsen, 2012) and social interactions (Hoban \& Nielsen, 2014), there has not been a study on the design process of making a slowmation as a digital teaching resource.

\section{Theoretical Perspectives}

Whilst most research on technology-enhanced learning in science has used either cognitive or situative theories as a focus (Russell \& Kozma, 2007), our theoretical framework for preservice teachers learning science through creating animations is semiotics, which is the study of signs, because slowmation is a representation. The slowmation process requires learners to make a sequence of literacy-based representations culminating in the final digital explanation with each representation being a sign or symbol of an event, content or experience. For example, slowmation usually involves preservice teachers designing a series of representations resulting in the final digital product (Hoban \& Nielsen, 2010) - Rep 1: summarising notes from information sources $\Rightarrow$ Rep 2: designing a storyboard to plan and break down the concept into "chunks" $\Rightarrow$ Rep 3: making models to show physical features $\Rightarrow$ Rep 4: taking still photographs of the manual movements of models to show how things move $\Rightarrow$ Rep 5: using movie-making software to integrate different modes of communication to make a narrated digital explanation.

Peirce (1931/1955) proposed three terms for meaning-making when creating a representation: (i) a "referent" is the concept being represented; (ii) the sign created is the "representamen"; and (iii) the meaning generated is the "interpretant". With the prevalence of personal technologies, there are increasing opportunities for students to represent content using different modes of communication (Hand \& Choi, 2010; Kozma, 2003; Lemke, 1998; Tytler, Prain, Hubber, \& Waldrip, 2013). According to Kress (2010), a "Mode is a socially shaped and culturally given semiotic resource for making meaning. Image, writing, layout, music, gesture, speech, moving image, soundtrack and 3D objects are examples of modes used in representation and communication” (p. 79, emphasis in original). Often students are encouraged to sketch their ideas, but with technology students can create and integrate combinations of modes to generate multimodal representations of science concepts. For example, when preservice teachers make a digital resource such as slowmation, they represent content through different modes such as still images, slow moving images, speech, writing and music (Hoban \& Nielsen, 2012) and use technology to integrate them in the final product.

Research has shown that creating a slowmation involves a transfer of meaning (the 'interpretant') from one representation to the next resulting in a narrated slowmation. This has been called a "semiotic progression" whereby the interpretant or meaning from each sign or representation contributes to the next representation culminating in the final narrated animation (Hoban, Loughran, \& Nielsen, 2011). Learning results because of the cumulative semiotic progression, where preservice teachers "[revisit] content through different semiotic systems with meaning building from one representation to the next to promote learning" 
(Hoban, Nielsen, \& Shepherd, 2013, p. 140). In a study of preservice elementary teachers creating a narrated animation to explain the Biology topic of the life cycle of a ladybird beetle, participants began with different levels of prior knowledge and then built knowledge iteratively as they checked and re-checked their information and created different representations, including the storyboard and models as well as the content on various Internet sites (the 'referent'). This provided opportunity to negotiate meaning and resolve an alternate conception (Hoban et al., 2013).

However, as with any student-generated representation, it is possible that the content could be misrepresented or misinterpreted because students may hold intuitive conceptions (Babai, Sekal, \& Stavy, 2010), misconceptions (Driver \& Erickson, 1983; Gilbert \& Watts, 1983) or alternate conceptions (Sequira \& Leite, 1991; Trumper, Raviolo, \& Shnersch, 2000). Such alternative conceptions are often deeply held and highly resilient (Cobern, 1996; Driver, 1983; Howes, 2002; White \& Gunstone, 1989). According to Hewson and Hewson (1984), students may hold an alternate view preferentially in spite of being taught otherwise. This preference may in some ways explain the resilience of the concept - it serves a functional purpose in terms of propositional (knowing that) and procedural (knowing how) knowledge. Teacher educators thus need instructional strategies to help preservice teachers review their prior conceptions, negotiate new meanings and perhaps resolve alternate conceptions.

According to Tytler and Prain (2010), representations play a critical role "as cultural artifacts in supporting reasoning and conceptual change as illustrative of the way language constitutes and shapes thought rather than acts as an after-the-event by-product of conceptual understanding” (p. 2060). More particularly, Prain and Tytler (2012) argue that thinking occurs through the creation of a representation. Creating a representation thus generates opportunities for discussion and comparing and debating ideas, which may be correct or incorrect, potentially resulting in clarification of ideas and conceptual change. However, alternative conceptions are resilient and they can remain static, may progress to be scientifically accurate, or even regress over time, especially if the concept is complex (Tytler, 1998).

The topic of "moon phases" is one such complex concept, especially for preservice elementary teachers. Previous research has shown that the concept is challenging to understand and alternative conceptions are common (Atwood \& Atwood, 1997). Trundle, Atwood and Christopher (2002) interviewed 78 preservice elementary teachers, half of whom had received instruction about phases of the moon and half who did not. The most common alternative conception is that the moon's phases are caused by the earth's shadow. However, the teachers' learning was fostered through instruction on phases of the moon as one of five topics during a semester-long physics course where they recorded daily observations of the moon. In a subsequent longitudinal study (Trundle, Atwood, \& Christopher, 2007), 12 female preservice elementary teachers were involved in a similar course over several months that targeted phases of the moon. The preservice teachers were interviewed on their understanding on the cause of moon phases before instruction, three weeks after instruction and in delayed post-interviews several months after instruction. Results showed that a majority of the students maintained a scientific understanding six months after the course finished. Another form of instruction involved 50 early childhood education students using a planetarium simulation called Starry Night Backyard for a full semester (Bell \& Trundle, 2008). As a result, $82 \%$ of the preservice teachers maintained their scientific understanding. In short, several studies have shown the benefit of preservice teachers participating in semester long courses with additional time spent on actual moon observations, simulations and modeling.

Science education research has extensively covered the topic of astronomy. Lelliott and Rollnick (2010) reviewed 103 articles about astronomy and education published between 
1974 and 2008 and noted, as did Bryce and Blown (2012), that most people (of all ages) have difficulty with moon phases as a concept. Even students who studied physics before their teacher education programs continued to have flawed conceptions after a full-semester, model-based astronomy course (Ogan-Bekiroglou, 2007). Both the length of time and the depth of the background knowledge of the students are problematic in elementary teacher education: there simply is inadequate time to provide or develop the depth of requisite knowledge. Thus, new strategies are necessary to have preservice teachers interact with science content so as to develop more meaningful understandings. Further, none of the research reviewed made explicit reference to creating a product as a digital teaching resource as a means to expose preservice teachers' prior knowledge and create opportunities to negotiate their understandings. The current study explored preservice teachers' learning while making a slowmation as a digital teaching resource focusing on the challenging topic of moon phases. The study was guided by the following research questions:

1 . What are the understandings of the preservice elementary teachers about the causes of moon phases before and after making a slowmation?

2. How did the preservice teachers design the slowmation as a digital teaching resource?

\section{Method}

The current study was conducted in November 2012 and used a case study methodology (Merriam, 1998; Stake, 1995; Yin, 2003) to map the learning of three preservice elementary teachers during the actual creation of a slowmation as a digital teaching resource to explain moon phases. The research time was deliberately limited to three hours as we wanted to investigate whether the preservice teachers could make a slowmation about a complex topic within the timeframe of a typical science method class. We framed our data collection, analysis and interpretation based on a social constructivist paradigm (Cobb, 1994; Johnson \& Gott, 1996; Mintzes, Wandersee, \& Novak, 1998), whereby social interaction between learners involving conversation and co-construction of artifacts may both reveal and develop conceptual understanding. The preservice teachers volunteered when we sought participants who had previously made a slowmation in their first year science methods subject. The group was allocated the concept "phases of the moon" at the beginning of the study, a concept about which they had no prior notice. We chose this topic because traditionally, it is a challenging concept for preservice elementary teachers (Trundle et al., 2002) but is a concept that they need to understand for the teaching of school curriculum.

We used a range of qualitative methods to study the creation process as our case students were given the task of creating a slowmation as a teaching resource to explain phases of the moon to elementary school children in Grade 6. We used a similar process to that reported previously (Hoban et al., 2011; Hoban \& Nielsen, 2013), but with a key difference - phases of the moon is a much more difficult topic with well-documented alternate conceptions, the most common of which is that moon phases are caused by the shadow of the earth which Trundle et al. (2002, 2007) called the "eclipse alternative conception". As soon as our case teachers were allocated the topic, individual interviews were conducted to ascertain their prior knowledge and science backgrounds. They were also asked to reflect on their own knowledge of moon phases. We asked such questions as: Can you explain the topic? Where will you look for information? How will you learn about the topic? We used these questions to get a sense of the preservice teachers' background understanding to gauge if these students held similar kinds of understandings (or alternate conceptions) previously reported in the research literature. Interviews were audiorecorded.

The actual slowmation construction process was captured on video and audio as our study volunteers talked aloud. We assigned pseudonyms for the three preservice teachers: Alice (A), Eliza (E), and Xena (X). Representations that they produced were also collected as 
data (e.g. notes, sketches, storyboard, models, photos, the narrated animation). Immediately after the animation construction was completed, the preservice teachers were again interviewed individually about how their knowledge had changed, guided by questions such as: Can you explain phases of the moon? What did you learn that was new? What was helpful to you for your learning? Were you surprised by anything? Thus, through the interviews, the preservice teachers were asked to reflect on what they knew (pre-interview) and what had changed (post-slowmation construction). The audio record was transcribed verbatim.

It should be noted that there was some previous preparation for the case study: (i) the volunteering preservice elementary teachers had completed the Bachelor of Education degree (four year program) and had previously made a slowmation in their first year science method course, so they were familiar with the slowmation process and use of their own technology; and (ii) the preservice teachers had completed a one-hour workshop in which they were encouraged to "think aloud" and articulate their thinking as they made a slowmation on a different topic. Further, the preservice teachers were working in a room designed for elementary science methods classes that was stocked with a collection of typical classroom resources such as cardboard sheets of different colours, a selection of polystyrene balls, scissors and other construction materials.

\section{Data Analysis}

The pre and post interviews and audio files from the three-hour construction were transcribed and the 104-page transcript of the utterances during the construction was crosschecked by both authors as they together reviewed the video of the whole process. Any observations of gestures and relevant activities to the research, such as preservice teachers making a sketch during discussion, were added to the transcript as annotations. To answer the first research question, data analysis of the pre and post construction interviews began by adapting a coding scheme initially developed by Trundle et al. $(2002,2007)$ that identified scientific and alternative fragments for understanding the concept of moon phases as well as alternative conceptions. Trundle et al. devised this scheme from extensive interviews with preservice elementary teachers and stabilized it through a constant-comparative methodology. Trundle et al. (2002, 2007) and Bell and Trundle (2008) identified four scientific fragments that were important to explain moon phases. The four scientific fragments along with assigned codes are:

(i) the moon orbits the earth (SciOrb);

(ii) half of the moon is illuminated by the sun (SciHaf);

(iii) the portion of the illuminated half seen from earth determines the phase (SciSee);

(iv) the relative positions of the earth, moon and sun cause the phase (SciEMS).

We have called these fragments "elements" because this complements a definition used by White and Gunstone (1992) to describe how meaning making or understanding is built. According to White and Gunstone, understanding is:

a function of the number of elements of knowledge that a person possesses about the target, whether the target is a concept, whole discipline, a situation, and so on, and of the mixture of different types of elements and of the pattern of associations that person perceives among them....The person's understanding develops as new elements are acquired and linked with the existing pattern of associations between elements of knowledge. Addition of new elements will often stimulate reorganization of the pattern as the person reflects on the new knowledge and sees how it puts the older knowledge in a different light. (pp. 12-13) 
Elements as fragments of knowledge depend on the nature of the "target" (i.e., concepts, whole disciplines, elements of knowledge, situations, extensive communications, people). In essence, developing understanding of a science concept is related to developing a reasonable grasp of the constituent elements and how they interrelate.

Furthermore, we added two elements that are important to characterize preservice elementary teachers' understanding of moon phases. The first additional element is derived from Fanetti (2001), who interviewed 50 college students and surveyed an additional 700 and found that the most common reason for students not understanding moon phases was their misunderstanding of the relative scale differences between the earth, moon and sun. We therefore included understanding of relative scale difference as a fifth element, coded as SciSca. Also, being able to name phases is important because moon phases are a key aspect of school curriculum and preservice teachers need to know the labels as a basis for helping children to understand the concept. Although the knowledge of names of phases could be seen as simplistic, all representations we could find of the scientific concept of 'moon phases' in physics textbooks, on-line encyclopedias and Internet Q\&A sites included names for the phases. Thus we feel justified in calling this an element of the concept and deserving of its own code, which we call SciPha. Furthermore, like other elements relating to the conception of phases of the moon described by Trundle and colleagues, SciPha is subject to partial representation by learners (or preservice teachers) as we noticed with participants in the current study. Table 1 shows these elements as well as the relevant codes, including the common alternate eclipse conception (AltEcl).

\section{[INSERT TABLE 1 ABOUT HERE]}

The two authors independently coded approximately $10 \%$ of the data set and then met to discuss and clarify interpretations. After several iterations we were able to achieve an inter-rater consistency of $90 \%$. We co-analysed interview data to assess the preservice teachers' background knowledge of phases of the moon, which alerted us to alternate conceptions or fragmentary knowledge held by each participant. We also analysed the video data and transcript of the discussion during the creation process and identified any elements or new insights noted by the preservice teachers during the interview conducted immediately following construction.

\section{Results}

To address the first research question we analysed the pre-interviews with each of the three preservice teachers and identified the elements of their understanding of moon phases using codes from Table 1 . Next, we tracked the transcript describing the design of the slowmation as a digital teaching resource to explain moon phases to elementary children. We identify elements of the concept throughout the data presentation as key analysis points.

\section{Conceptual Understandings of Moon Phases Before and After Slowmation Construction}

Eliza. Eliza described her background knowledge as "very poor" and questioned her own readiness to be an effective teacher of science in an elementary classroom. She was asked what caused the phases of the moon:

It's just the interaction between where the sun is in relation to the Earth and in relation to the moon (SciEMS). So from the Earth you can see the way the light is either passing, it can pass the Earth to the moon or when the moon is in between, you know what I mean? The shadows are because the moon is in between the sun and the Earth and therefore no light can pass through the moon to Earth (AltEcl)....So the shape is when the moon is like in a position where the light can get to it but it's on a different side to the Earth. So if you can see this half of the moon it would be on the left side, 
and if you see that half of the moon, it's on the other side, so it's just moving around like the orbit of the moon (SciOrb) and it's the earth's shadow (AltEcl).

Eliza articulated parts of two scientific elements (SciEMS, SciOrb) as well as the eclipse alternative conception (AltEcl). Her explanation identifies the elements, but also represents her limited prior understanding.

Immediately after the slowmation construction was completed, Eliza articulated a better understanding of moon phases, but retained the AltEcl conception:

So the moon is rotating around the earth and that takes a month, 29 and a half days (SciOrb)....It's all about the position of the moon in relation to both the earth and the sun (SciEMS) so depending on where the earth is, the moon rotates around the earth and depending on where it is in its orbit, the light from the sun will cast different shapes depending on the shadow of the earth and whether the light can get to the dark side of the moon (AltEcl)....if the moon is between the earth and the sun, from the earth you'll see a new moon because the light from the sun is blocked by the moon and then when it rotates clockwise you'll see partial light onto one of the sides of the moon and as it moves around, the light is greater so it goes to the crescent and then the gibbous, then the half moon and then when it's completely behind the earth, the sun shines on the full face of the moon, so it's called a "full moon" and then it does the opposite as it goes back around (SciPha).

In articulating three elements, Eliza does so with much greater detail, even though it appears she retained part of the eclipse alternative. Later in the post interview, she described a fourth element:

I hadn't thought about it in 3D where the sun is a lot bigger than the earth and can shine past the earth onto the moon (SciSca)....I thought the shadow of the earth would block all of the sun from the front and I thought two new moons happened, one when it was behind the earth and one when it's between the sun and the earth....I thought it was black on the other side of the earth - the opposite side of the sun. But I then learned that because the sun is so large (SciSca) and the moon is a little bit away from the earth, that the sun actually, its light goes around the earth and you can see the full moon from the other side.

Eliza attributes her own prior misconceptions (alternate eclipse, two new moons) to not understanding the scale difference between the sun and moon. This difference became apparent to her when she realized that the sun is large enough to shine past the moon and thus be visible from the earth. The addition of the Scale element during the creation of the slowmation helped to resolve her misunderstanding about two new moons. In summary, before the slowmation construction, Eliza articulated parts of three elements and the eclipse alternative conception. After making the slowmation she identified four elements as well as the alternative conception.

Xena. Xena described her science ability as "average to good," but in the pre-interview, she was asked to explain the phases of the moon and her weak prior knowledge includes only one element:

I know that there's a new moon and at one point there's a full moon and a half moon (SciPha) but how and why that all works, no, I'm not very sure. It's not something to do with the currents because the moon affects the way that the tides work so it's not that way around so, no, I don't know....I know that the way that the moon is in the sky affects the way that the tides go because of something to do with the gravitational pull, but aside from that, I'm not really sure.

Realizing some relationship between the moon and tides and that there were different moon phases indicates her limited prior knowledge. However, after the slowmation was created, Xena identified three elements in explaining moon phases: 
I understand that the sun shines on the moon (SciSee) and depending on where the moon is relative to the earth, the sun creates the different phases (SciPha, SciEMS) of what we can see in the sky....The earth rotates around the sun - either it's anticlockwise but it looks clockwise and then the moon rotates around the earth anticlockwise but looks clockwise or it could be flipped around - it's one of those two (SciOrb). So it rotates one way but it looks the other....I don't think I'd actually really thought much about it before. In the pre-interview when they asked about phases I couldn't really give an answer; I hadn't really given any thought to it.

In summary, before construction Xena had weak conceptual knowledge identifying only one element whereas after construction she identified three elements.

Alice. When asked to explain moon phases, in the pre-interview Alice identified parts of two elements:

I think it relates to a cycle of the moon, the different shapes that we see and its position in relation to the earth or something (SciEMS)....I think it's got something, I really don't know, I think it's something to do with the orbits (SciOrb), because when I think about the moon I think about the tides and there's like lunar calendars that are to do with the tides I think.

After completing the slowmation and in describing what she had learned, Alice described four scientific elements of the moon phase conception:

I learned about how the moon orbits the earth (SciOrb) and how it doesn't have a natural light, that the sun's light and the shape that is made by the light reflected by the sun determines the different phases (SciSee) and there are eight phases (SciPha) and it takes 29.5 days for the moon to orbit the earth (SciOrb). The eight phases have different names and I've learned the names of them, I didn't know them before.....we didn't actually know that it was to do with the positioning and the sun and everything (SciEMS) and that it was not the earth blocking the sun's light casting a shadow....We found that it was mainly to do with the orbiting and movement and things like that (SciOrb).

Her earlier partial understanding of the two elements was much more coherent and detailed as she articulated her understanding in the post-construction interview. Additionally, Alice described two more elements with links between them.

Table 2 summarizes the apparent changes to the preservice teachers' understanding of elements of the moon phases concept. Data suggest that the process of constructing the slowmation helped them to develop more elements resulting in a deeper understanding of the concept. Noting the areas of improvement to our preservice teachers' understanding, we now move to explain these changes through the process of creating the slowmation as a digital teaching resource.

\section{[INSERT TABLE 2 ABOUT HERE]}

\section{Designing the Slowmation as a Teaching Resource}

In this section, we track the creation of the slowmation as a digital teaching resource. We include Table 1 codes when an element or alternate conception is raised in a given episode, and identify the page and line numbers from the full 104-page transcript in parentheses. 
Step 1: Clarifying the task. As soon as the individual interviews concluded and to initiate the slowmation construction process, the three preservice teachers sat around one laptop computer and clarified the task at hand while searching for information about the topic (p. 1, lines 16-21):

A: All right. So I guess we Google 'phases of the moon' shall we? I'll just access the Internet.

E: What do we actually want to put in there?...(e.g. in the slowmation)

A: $\quad$ Okay, so our audience is Year 6 so I guess it would be the different.

E: Yes, because we're teaching it... Could we even look up the syllabus and see, use that to guide.

Alice initiated a search in the rest of the on-line version of the New South Wales K-6 Science \& Technology Syllabus (NSW Board of Studies, 1993) ${ }^{1}$ to identify where 'moon' appears (p. 6, lines 20-27):

A: $\quad$ This is for a Stage 2 audience. [Years 3-4]

E: 'Observes and records phases of the moon over time, proposes explanations and uses other sources to verify their ideas. (E reads from Stage 2 Syllabus outcomes).

A: Okay.

E: That's what we're doing.

A: $\quad$ So 'records phases and explains them'? (SciPha)

E: Yes.

Satisfied that they had identified the relevant portion of the official curriculum, they read the curriculum document more carefully to identify key words, ideas and concepts that children are supposed to learn in the unit searching for both content knowledge and curriculum information regarding phases of the moon. This involved questioning and decisions around material that was suitable to present in an explanation for children, the amount of detail to include in the slowmation and overall length of the teaching resource they were designing. In summary the preservice teachers clarified that they were designing a resource to teach a part of the syllabus to elementary children and they made use of the official curriculum document in considering how to develop a resource to explain phases of the moon.

Step 2: Developing understanding of the concept. Once the participants clarified the purpose of the resource, they set out on Google searches for more information about the concept. Because their focus was on creating a resource for children, they narrowed the search to explanations presented at a suitable level for children (p. 8, lines 18-22):

A: Now I think we should do "Phases of the moon for kids" because

E: Well that came up automatically.

A: That just came up and I think that will help me understand it.

E: Yes, because otherwise you could get really advanced explanations. That is a good idea; I wouldn't have thought to put in “for kids”.

This demonstrates an important awareness on the part of these preservice teachers about both the limitations of their own understanding and the need to explain content at an appropriate level for children. This is often a challenge for novice teachers as their own understanding of science content can be quite shallow. Thus, they need to develop some understanding in order to develop an explanation or explain the concept to children.

During this step, the group found and recorded 'fun facts' about the moon and the moon phases, including that the moon travels around the earth (SciEMS); the moon orbits above the earth's equator (SciOrb); there are eight phases of the moon (SciPha); the phases

\footnotetext{
${ }^{1}$ Since this research was conducted, a new National Curriculum has been introduced in Australia, with new syllabus documents prepared at the State level. (See New South Wales Board of Studies, 2012).
} 
are named after the portion that is visible (SciSee); and the earth's axis is tilted which gives the moon a changing appearance through its cycle. They also noticed aspects of the concept that were new to them, such as when the new moon occurs and when the moon is visible during the day. In discussing the information they encountered, they became aware of the state of their own background knowledge and experience that may be different for others ( $p$. 15, lines 19-21):

$\mathrm{X}$ : I don't actually remember looking up and not seeing the moon.

E: I'm going to look every night now.

A: I remember as a kid it used to make me, I didn't understand why in the day you could sometimes see the moon. (SciSee)

The preservice teachers also asked many questions about the relative positions of the earth, moon and sun (SciEMS); the shape of the moon's orbit (SciOrb); and how the various facts they were finding fit together. Some of this information is very basic, but typically reflects preservice elementary teachers' weak knowledge of general science concepts. An important part of their explorations involved seeking a more coherent understanding of the concept for themselves. As Eliza noted, "we're just trying to understand it ourselves" because "when you're teaching it you have to know it a lot better" (p. 21, lines 18-21).

During this process of learning enough about the concept in order to explain it to children, they repeatedly revisited and clarified this goal by way of synthesising what they wanted to convey in the slowmation and what they wanted the children to understand (p. 23, lines 11-16):

A: $\quad$ So basically for a kid, we want to say, what are our key... what do we want to get across?

A: 'There are these phases, they're that long, there’s eight of them' (SciPha) - we'll maybe explain what they are

E: Yes and we want them to understand the interaction between the sun, the earth and the moon. (SciEMS)

A: $\quad$ Yes, essentially.

E: And do we leave it at that?

A: Basically I think yes because then we can go into detail; it's plenty of stuff.

They also found videos and other slowmations showing phases of the moon and considered these as possible examples for the teaching resource they were making (p. 27, lines 4-5):

A: [responding to a YouTube video explanation] That's a good way of saying that - that the moon doesn't generate light; it's just from the sun (SciSee). I think that's a good way of explaining it to kids instead of saying 'The sun reflects...' You know what I mean?

E: Well I don't know. I feel like I want to do a demonstration because like flat pieces of cardboard is not really showing the light and the shadow and you're not getting why it's changing.

Viewing other examples helped our preservice teachers to identify relevant information and consider how to include it in the explanation. Importantly, to generate an explanation, the creators need to know enough about the concept in order to explain it, so a focused search helped our participants avoid unnecessarily complicated information (that they perhaps would have difficulty understanding themselves or explaining to children). They found a number of information pages in their Google search and about 42 minutes into their work, found a YouTube clip of an interview with an elementary teacher who explained the cause of moon phases incorrectly by portraying the eclipse alternative conception:

What causes phases of the moon? If I had to guess, I don't know for sure, but I think it's how the earth casts a shadow on the moon (AltEcl). So if the moon is on one side of the earth and the sun is on the other side and so when 
we see a crescent on the moon, the earth is blocking out that dark area and the sun is shining on the sunny side.

Viewing this clip triggered a debate among the participants (p. 29, lines 8-23):

A: $\quad$ So that's wrong, is that right? [Alice challenges the statement on the video]

E: $\quad$ They make me feel bad for not knowing.

X: I thought that was right.

E: I thought it was right; that's what I said in my interview.

A: But didn't he say that 'Here's the earth and the moon is on one side and the sun's on the other side'? Is that what he just said?

$\mathrm{X}$ : $\quad$ He started out saying that but then he explained it a little further. He said, yes, if there's only a crescent that means the sun is only shining on part of it and the earth is blocking the rest. (AltEcl)

A: $\quad$ Yes, but everything else that he said makes sense except when he said that.

E: $\quad$ Yes, we shouldn't laugh; this is me.

A: But it's not about the earth blocking it, it's about the sun's isn't it? The earth doesn't block the sun.

$\mathrm{X}$ : It does.

Eliza and Xena both recognize that they share the same conception (AltEcl) with the interviewee from the YouTube clip. Xena is more tentative about her understanding than Eliza ("I thought that was right") while Alice tentatively recognizes the depiction as incorrect. We see both the tentativeness and recognition of different understandings as important steps in the process of preservice teachers developing their own understanding of key curriculum concepts, and in this case, while learning enough about the topic to co-create a slowmation. As the group continued to gather information, Eliza made sketches and summarized facts. Further, she drew the earth and sun with the same relative size (see Figure 1) to explain how the phases were generated, and further, she used the representation of positions of the earth, moon and sun to explain the phases to the others (p. 30, lines 2-9):

E: $\quad$ Okay, think about it - I can't do it without it being in $3 \mathrm{D}$ - but if the moon is here and the earth is here, if the sun and the moon go around...well the sun doesn't go around but if they're....[pointing at the moon, earth or sun as she makes her case] (SciEMS)

A: $\quad$ Yes. No, I thought just then when he said that, I was assuming that he was talking about the moon being lit up already and the earth blocking it (AltEcl) instead of the sun providing the illumination (SciSee). OK, oh yes, yes, I see what you mean, which we've learned though.

\section{[INSERT FIGURE 1 ABOUT HERE]}

As Eliza justifies her thinking in reference to the relationship depicted in the sketch, Alice and Xena are trying to understand the point of view. Eliza then asks a question about sufficiency of the information collected thus far (p. 31, lines 6-9):

$\mathrm{E}: \quad \mathrm{OK}$, do we need to know anything else?

$\mathrm{X}$ : $\quad$ This has to do, like the axis of the earth has to come into play on this because if we think back to the first video we saw, when it's the sun and then the moon and then the earth (SciEMS) - that's when it's a new moon and you can't see it.

E: Yes.

$\mathrm{X}$ : $\quad$ So when is it a full moon then?

Xena asking about the full moon triggers and focuses the group's attention on relevant information in Eliza's sketch (p. 31, lines 10-18): 
E: Maybe when it's completely on the side [above and below the earth in the sketch] because you can see all of the sun's light is being reflected. (SciSee) [gesturing with her hands showing the moon on the side of the earth]

$\mathrm{X}$ : $\quad$ So if the earth is like this [gesturing] then it has to be like when the sun and the moon are close to each other? (SciEMS)

E: $\quad$ Yes, yes.

$\mathrm{X}$ : Because it has to be where the sun can reflect off of it but it's still in the position where we can see it. (SciSee)

A: $\quad$ We can see the whole thing, yes.

$\mathrm{E}$ : $\quad$ So the angle of the reflection is towards earth.

A: Because you would think that the sun would have to be there [pointing]. Here's the moon. The sun would have to be there to be able to see it. [pointing to sketch]

$\mathrm{X}: \quad$ But it depends where the earth is. (SciEMS)

E: We're seeing it. It's not when you're on the moon.

While Eliza uses the sketch to explain her understanding of the relative positions to Alice and Xena, the explanation is not clear and so Xena repeats her question about the full moon (p. 31, line 23): "So I wonder where the earth needs to be in relation to the moon and the sun for it to be a full moon?” (SciEMS, SciSee). There are discrepant views and misunderstandings of the information and the on-going discussion is attempting to reconcile the information (p. 32, lines 4-5):

E: I don't know. There would be two full moons, one here and one here [again pointing to her own sketches in Figure 1 showing the full moon above and below the earth and the earth and sun as the same size]

$\mathrm{X}$ : $\quad$ But there's only one. Isn't there only one full moon in the phases because there's a new moon there [pointing to a Google Image that Alice found showing a still image of each of the moon phases in a line, each named and only one new moon]

Eliza states her prior conception (that there are two new moons in a cycle) and justifies the view with the sketch she made. Xena then challenges this as Alice tries to refocus the group's discussion (p. 32, lines 6-11):

A: $\quad$ So there are eight different phases. [referring to the Google Image] (SciPha)

$\mathrm{E}$ : Why is there not two [full moons]?

$\mathrm{X}$ : Well that's what I thought. Why is there not two? [Xena agreeing with Eliza]

A: That looks like, there's not two. So it's right in the middle [of the lunar cycle]: One, two, three, four, five, six, seven, eight... [Alice counts the phases depicted in the Google Image]

E: $\quad$ And then what does it do? It goes black and then goes back to there.

Xena and Eliza use gestures to model relative positions, and Eliza keeps returning to her conception that each cycle has two full moons. Eliza's misconception (e.g. two new moons and two full moons per cycle) is resilient even as it is challenged by her group members and the information in the Google Image. This provokes continued discussion among the group.

Eliza is both trying to make sense of the idea and convince the others of the concept's viability (p. 32, lines 13-24):

E: $\quad$ It's a cycle.

A: $\quad$ So it's a cycle, there are eight phases. (SciPha)

E: Why is there only one [full moon]? So okay. So it's black here and it's also black here. [looking at her sketch again] Are there two phases per orbit? No, there isn't.

A: $\quad$ No, because there are only eight phases per cycle.

$\mathrm{X}$ : It's not black in two spots either; it's only black in one - there's only one new moon and it's right here. [Xena pointing to the sketch showing the moon on the opposite side to the earth] 
E: Then what happens on this side when the earth is completely blocking it? (AltEcl)

$\mathrm{X}$ : That's when it's full; see this is what happens. [pointing on sketch to where sunlight can reach]

$\mathrm{E}$ : Oh duhhhh, because the sun is massive, like the sun is huge. [Eliza realises the large difference in scale between the sun, earth and moon and so the sun can shine past the earth onto the moon thus making a full moon]. (SciSca)

$\mathrm{X}$ : $\quad$ Our issue is because we are not seeing it in 3D.

$\mathrm{E}$ : $\quad$ Because the sun is huge, the sun can still light up the moon from the other side. (SciSee)

The idea of two full moons could be supported because of the incorrect scale depiction and by positioning the full moon(s) above and below the earth in the 2-dimensional sketch. When Eliza realized the significance of this misrepresentation, it also became clear why there was only one full moon and that the sun's light was not blocked from reaching the earth just because the moon was between the earth and sun. In this discussion, they were trying to make sense of how the phases were generated and they described several elements of the concept. Their discussion was significant as they continued to develop their own understandings and plan for the slowmation.

Step 3: Planning the sequence of sub-concepts or chunks. In order to begin planning a sequence for the slowmation, the preservice teachers need to feel that they have adequate understanding of the concept and this involves breaking it down into components or subconcepts. They decided to model parts of the concept as part of their planning process. They searched through the various construction materials available and chose polystyrene balls and mounted them on sticks as models of earth and moon (e.g. representamen). When moving the models in relation to each other, Xena asked, "Did we determine which way the moon rotates around the earth? Is it clockwise or is it counter-clockwise?” (p. 40, line 19). This is a detail question prompted by model building. Further, Alice recognized the thinking involved in the model construction: “By playing with this model, we've realised that we don't actually know if the [moon] orbits the earth in a clockwise or an anti-clockwise direction” (p. 41, line 1) (SciOrb). Alice searched the Internet for an answer so as to depict the movements of earth and moon accurately.

They also conducted a trial run with the model set-up to demonstrate the relative positions of the earth, moon and sun and generate the different moon phases. Importantly, in creating the models they made an important sequencing decision to begin with the new moon and used a storyboard to sequence the rest of the phases of the moon. The storyboard is an important representation for organizing sub-concepts into a coherent sequence. In this case, the phases of the moon provide a natural sequence for the explanation (p. 54, line 26 to p. 55, line 16):

A: All right so for the purposes of the storyboard - 'The moon moves around the earth' maybe we can just take some pictures of the moon going around the earth. (SciOrb)

A: $\quad$ Yes, 'It takes 29.5 days as it moves around the earth, the sun...'

$\mathrm{X}$ : That's going to be awesome.

A: 'The sun reflects light onto it in different ways and at different angles depending on its position.' (SciSee)

E: It's clockwise. I've been going the wrong way.

A: $\quad$ Okay, so then 'There are eight... each particular thing is a phase...' (SciPha)

The planning made them revisit the concepts they were trying to represent in the explanation. Thus, they returned to their notes, models and the Internet and tried to sequence the subconcepts as chunks of information on the storyboard. They debated typing up the narration, but opted instead to hand-write the script which helped to consolidate the plan for the sequence (p. 58, line 14 to p. 59, line 8): 
E: Ok, so plans are good. So 'Phases of the Moon. The moon orbits the earth (SciOrb). It takes 29 days to do so...'

A: $\quad$ Yes, okay. So we've said that. So 'Phases of the moon. The moon orbits the earth. It takes 29 and a half days to do so. As it's moving around the earth, the sun is...' where does the sun move?

E: We don't talk about the sun.

A: ' '...the sun shines light on the moon.' (SciSee)

E: Yes.

A: ' '...depending on the position of the earth...' (SciEMS)

E: And make sure you say 'the moon doesn't emit light — the sun does the light on the moon.'

A: ' '...sun shines on the moon.' And then I think it's written here perfect and 'that's how we see the moon from earth.' Okay. 'There are eight phases...'

E: Well, depending on the shape of the light on the moon and then maybe we'll show what they are.

A: $\quad$ Yes, and say that at the end - 'There are eight phases that are named after the amount of light that we can see.' (SciPha)

While planning for the sequence of sub-concepts, the preservice teachers revisited elements and clarified what they were going to represent in the slowmation.

Step 4: Making and photographing the sequence of sub-concepts. Satisfied with their plan for explaining the moon phases, the preservice teachers began to take photos as they manually moved the models. Figure 2 shows the photographic set-up and two of the preservice teachers manipulating the model system. Much of their dialogue involved procedural considerations, but they were trying to accurately depict the moon phases as subconcepts in the photographs.

\section{[INSERT FIGURE 2 ABOUT HERE]}

They also regularly stopped, checked and confirmed information from the Internet (p. 74, line 26 to p. 75 , line 14 ):

A: Can we just see what it looks like if I can get it all on the screen? [Alice takes photo of changing shape of light to see if it shows up on the camera] Ok so the start would be that.

E: $\quad$ Should I cover it half so we've got that half rather than...?

A: Well what does the information say? Let's just quickly look at the diagram. The diagrams - do they match? On the Internet... oh dear, look at this. We got this bit right... [Alice checks that the phases being depicting for the slowmation match the photographs they found on the Internet]

As they followed their plan for generating the images of the various moon phases, their ongoing dialogue was focused on producing the desired moon shape, but also involved further questions and checking of their interpretations. At one point, the preservice teachers realized the need to consider the perspective of the viewer, as Alice snapped pictures and Eliza moved the models (p. 80, lines 2-8):

E: $\quad$ Tell me when it's a crescent.

A: $\quad$ start again.

E: No, no, but you need to move it each time...you're pretending you're on the earth for this because you want to see the phases. That's the problem with our model really, the fact that we're not standing on the earth.

By virtue of the position of the camera to take stills of the system (including earth, moon and sun), the preservice teachers realized that the perspective for the resulting slowmation was 
going to be somewhere out in space and not from earth, as they had planned. This is a significant point as many of the images they encountered on the Internet also showed the earth, moon and sun system from space, a viewpoint which their students will likewise encounter and perhaps be confused by. As teachers, being aware of the different viewpoints represented in images is part of a wider modal awareness of different representational forms, which is important for their understanding of how to explain the concept. In generating a sequence of moon phases as sub-concepts, the preservice teachers focused on accurate depiction of the shapes for the phases and relative positions for the earth, moon and sun. Once they took photographs of all the planned still images, they moved to finalize the slowmation.

Step 5: Narrating the sequence. The actual slowmation was made by uploading the still images into Windows MovieMaker on Alice's computer. Windows MovieMaker displays the images as a digital slide show and becomes a more effective explanation when additional features complement the still images. Features include a narration, captions or labels and timing of the individual images. For example, a still image can be set to stay on the screen longer as a 'static image' enabling further exploration of a concept or to emphasize a particular point of the explanation. The preservice teachers make many decisions about aligning the modes of still images, slow moving images and voice narration so that the presentation of sub-concepts has a coherent structure in the final movie that explains the concept (p. 89, lines 7-19):

A: $\quad$ So what are we going to be saying while this is going on?

$\mathrm{X}$ : 'Phases of the Moon.'

$\mathrm{E}: \quad$ the moon...

X: We didn't take enough pictures.

E: $\quad$ Sure we did.

A: We'll just pause on some.

$\mathrm{E}$ : or get some Google images or something...

X: Well, we've got about three or four different models of how the phases of the moon go, so we can probably just

A: $\quad$ So this is when we're saying, 'The moon orbits the earth.'

Alice went back to the Internet to search for possible Google Images to include as still images to support the explanation in the slowmation. The group also decided to say the names of the phases in the narration and write captions so as to align the explanation with the image being displayed. In choosing words for the narration, they had to clarify terminology since they had not yet attended to the actual names for all of the phases. Alice and Eliza read from a website, which they used as a model for their narration (p. 93, lines 6-15):

E: 'The sun shines light on the moon (SciSee). The shapes that the light make are called phases.' Then, 'There are eight phases of the moon' and then (SciPha)

A: 'Phase one'

E: Just say the names.

A: Ok. Phase one is what? New moon?

E: Yes.

A: 'New moon'. No worries. All right, then, 'The phases are named after the shape. (SciPha)

E: $\quad$ Yes, that's this bit.

A: Okay, 'New moon', Phase two is the... what is it?

E: hmmm.

A: We don’t know yet. We're about to learn: 'The waxing crescent'.

The group went on to name each of the eight phases in turn. This revealed a mistake in the pronunciation for the phase 'gibbous' (p. 93, line 14 to p. 94, line 3): 
A: First quarter. Okay. First quarter. Then what? Then what's next?

E: This is crazy.

A: 'The waxing gibbons' before the

$\mathrm{X}$ : $\quad$ Oh, the waxing...yes

$\mathrm{E}$ : Oh, but it's this way, a little bit left. [gestures the curvature]

A: But it's that way, so it's this one. [points at Google Image]

$\mathrm{X}$ : hmmm

A: $\quad$ Yes, the waxing gibbon-it's nearly there, on this side.

E: $\quad$ Oh yes, but the curve's wrong.

A: The curve's going the wrong way. Is the curve wrong?

E: Yes.

A: $\quad$ Are we doing this one?

E: It's going outwards; it's like a convex.

A: What way should it be going?

In checking the information on the Internet and gesturing the direction of the curve, Alice realized that the image they took for the 'waxing gibbon' phase was facing the wrong direction. Alice tries to clarify the proper shapes for the sequence, and eventually uses the Paint program to draw in the proper curvature for the gibbous moon to complement a still image found on the Internet. She also realizes she had mistaken the name of the phase (p. 95, lines 11-27):

A: And what's it called? A gibbon?

$\mathrm{X}$ : $\quad$ Like the bird?

E: $\quad$ Like the monkey.

A: I swear I saw 'gibbon'. Did I see ‘gibbon'?

E: $\quad$ No you did.

A: Didn't I?

E: I just don't know how it's related...

A: Now, what's it called?

E: $\quad$ There it is.

A: It's not called the 'waxing gibbon.' It's called the 'waxing gibbous.'

E: Oh, 'gibbous.'

Clarifying the names of each phase and corresponding shapes continued as the group worked through the remainder of the eight moon phases. Checking and rechecking names and shapes in order to get the proper sequence for the explanation continued, and this provided additional opportunity for the preservice teachers to question their own understanding as well as clarifying what would be represented in the final slowmation. They also rehearsed the narration multiple times and adjusted the timing of some images so as to align voice and image. They reviewed the product by playing the movie several times, making adjustments to the length of time a particular image remained, the specific words used in the narrated explanation or added captions to offer additional explanation to the image/narration combination.

The 60-second slowmation identified and explained phases of the moon. Both the narration and the slowmation are supplied as Supplemental Material. The phases of the moon were represented in the following sequence: new moon; waxing crescent; first quarter; waxing gibbous; full moon; waning gibbous; last quarter; waning crescent. There was a consistent pattern in the slowmation with each phase introduced by showing a still image of the models in the correct orientation followed by an actual picture of the moon phase with a label and description of the phase through the narration. Figure 3 presents images from different parts of the slowmation. 


\section{[INSERT FIGURE 3 ABOUT HERE]}

In summary, in designing the slowmation, the preservice teachers first needed to clarify the task, then get an overall understanding of the concept of moon phases that was broken down into sub-concepts or chunks of information. They thus revisited the elements of the concept of moon phases multiple times in constructing the sequence of representations resulting in the final slowmation as an explanation of moon phases for children. Through making an explanation consisting of a sequence of sub-concepts and represented with different modes, the preservice teachers also learned about the concept. Table 3 summarises the design process showing the sequence of sub-concepts identified as well as the various modes of communication used to represent them.

\section{[INSERT TABLE 3 ABOUT HERE]} learning:

In her post-construction interview, Eliza summarised the overall process of their

As we went along, people were learning from the different things we were doing. We started with the websites but that didn't really trigger our thoughts whereas different tasks triggered our thoughts. I think because we went through so many different stages - we had the planning, we wrote down our background information, then we had drawings, then we went into the 3D models that made us reflect more on what we were doing and we had to constantly go back and think, 'Does this connect with what we were saying before?'

\section{Discussion}

The concept of moon phases is a challenging concept to understand for school students as well as preservice teachers as evidenced in many studies (Callison \& Wright, 1993; Fanetti, 2001; Sadler, Gould, Brecher, \& Hoffman, 2000; Trundle et al., 2002). Whilst research has shown that preservice teachers can develop understanding of moon phases, in most studies the concept has been part of a semester long physics course supported by nightly observations (Trundle, Atwood \& Christopher, 2007) or planetary simulations (Bell \& Trundle, 2008). Unfortunately, the extensive content that elementary trainee teachers need to know makes prohibitive the running of semester-long courses on all aspects of content. For this reason, teaching and learning approaches are needed that can be incorporated into shorter time spans such as in a science method class to engage preservice teachers in articulating, representing and negotiating their beliefs about content (Tytler \& Prain, 2010), especially ones that may contain misconceptions.

With regard to the first research question, the current study showed that creating a slowmation supported the three preservice teachers in developing scientific elements to help build understanding of moon phases. For example, constructing the slowmation supported Eliza in adding two elements to enhance her understanding; Xena progressed from one to three elements; and Alice progressed from two to four elements. Eliza articulated the AltEcl conception prior to the slowmation construction, which was likely reinforced because a YouTube video they viewed presented the same misconception (that the earth's shadow on the moon causes the phases). Further, when Eliza drew her sketch (as shown in Figure 1), she showed no scale differences and thus struggled to realize that there were not two new (or full) moons. This was resolved after discussion amongst the group and constructing further representations. In summary, each of the three preservice teachers increased the number of elements underpinning their understanding of moon phases during the creation of the slowmation. 
Creating a slowmation as a digital teaching resource therefore developed the preservice teachers' 'representational resources' (Tytler \& Prain, 2010) because the creation involved multiple interplays between creating representations as representamen and viewing representations created by others as referent. The preservice teachers developed a series of representations as a "semiotic progression" that resulted in an increase or "cumulation" in the number of scientific elements about phases of the moon (Hoban et al., 2011). Hubber, Tytler and Haslam (2010) argue that students need to understand diverse representational modes and how to use them to represent science concepts. The interplay between internet sources and the case students' note-taking, planning and model-making for the slowmation was apparent as they moved between interpreting the internet sources and generating their own representations in a connected sequence.

Research in student-created representations clearly shows that they are a window into their understanding and meaning making (Haim, 2010; Tang Delgado, \& Moje, 2014; Tytler et al., 2013), however, drawings as representations of understanding are often incomplete (Moseley, Desjen-Peroth, \& Utley, 2010), which we saw in the current study. Studentgenerated models are also likely to be incomplete, for example, ball and stick models made to represent aspects of phases of the moon. The extent of the understanding represented in a particular diagram, discussion or model is difficult to gauge, and as a subset of changes in understanding while producing a sequence of representations, even more so. We are mindful of other research indicating that students generally have weak abilities in translating between macroscopic and microscopic levels of phenomena (Al-Balushi, 2013), and there are different kinds of spatial thinking (Hegarty, 2014), suggesting that opportunities to consider spatial relations are valuable for preservice teachers. Further, this suggests that pedagogies that require the students to manipulate a variety of representations, both referent and representamen (of one central concept), in the process of developing an explanation as a teaching resource, has potential to help them consider relationships between different representational modes and develop more sophisticated understandings as prior conceptions are challenged.

Creating the multiple representations presented many opportunities to have their alternate conception(s) and elements that underpinned the concepts challenged, discussed, negotiated and revised. Importantly, the stop-motion construction process was halted several times enabling preservice teachers to check, discuss and revise information (Hoban \& Nielsen, 2014). Thus the construction process enables an ongoing interplay between existing knowledge (interpretant), content from the Internet such as Wikipedia or YouTube clips (referent) and the ideas being documenting in the representations (representamen).

In addressing the second research question, designing the slowmation as a digital teaching resource involved multiple steps for the preservice teachers: (i) clarifying the task; (ii) developing understanding of the concept; (iii) planning the sequence of sub-concepts or chunks; (iv) making and photographing the sequence of sub-concepts; and, (v) narrating the sequence. The design steps each comprise part of the digital explanation and we argue that there are important links between generating the slowmation as an explanation and the preservice teachers' learning of science.

Research in cognitive science provides a view of why generating an explanation is a good way to learn. Lombrozo (2012) outlines three reasons: the focus of the explanation constrains the learning task; in developing an explanation, one must process other explanations and hence, learn from them; and the process of generating explanations "be it for oneself or others, can influence one's own understanding and ability to generalize to novel contexts” (p. 7). Lombrozo recommends further research to study the process of generating an explanation. She argues for this because to date evaluating the quality of an explanation (such as what instructors do in marking assignments) is easier than understanding the process 
by which the generation influences learning. However, a recent study did clarify that explaining and expecting to teach a concept "appears to encourage effective learning strategies such as seeking out key points and organizing information into a coherent structure" (Nestojko, Bui, Kornwell, \& Bjork, 2014).

Our study shows how preservice teachers perform the strategies of seeking out key points and organizing information as well as the important role of creating representations in making a digital teaching resource. In short, this study details a process in creating a digital teaching resource that is multimodal. Similar to Fiorella and Mayer (2014), coupling the planning to teach with actually developing a digital resource plays an important motivational role for preservice teachers in learning the content that is to be represented. We argue that the main benefit of having preservice elementary teachers create a slowmation is that they have to think about how to best explain the content to school children and so clarify the task/content; identify main ideas; break the main ideas down into chunks to be sequenced and displayed; model and show the parts of the concept; and show how the chunks are related by rendering them into a coherent narrated sequence that explains the concept to children. Moreover, the creation is a process that encourages preservice teachers to revisit the concept multiple times and for multiple purposes. The process is therefore dynamic and recursive providing multiple opportunities for the preservice elementary teachers to clarify, share, and negotiate their beliefs to develop more elements to underpin their conceptual understanding.

\section{Implications}

Slowmation as a media-making process can be used within the timeframe of a science method class where building a digital explanation means that preservice elementary teachers 'think like teachers' in designing a teaching resource. Creating a slowmation as a teaching resource is a process that takes only a short amount of time, particularly in comparison to other interventions reported in the literature. The strategy could therefore be implemented independently as a three-hour class or to complement existing instruction and be used as part of a semester-long science methods course. Even within this short time frame, preservice teachers show deep engagement with science content knowledge. For an assignment, our students typically spend 5-8 hours developing a slowmation. During this time (in addition to the three hours of in-class time), the preservice teachers refine their ideas and further engage with science content.

In designing the resource, they need to understand the concept in order to break it into sub-concepts that need to be sequenced and then make multiple choices about how to represent the sub-concepts digitally. As such, the preservice teachers experience learning as will be expected of the children in their classrooms. In addition, we have found that in the process of constructing a digital explanation, many questions are raised that can be shared during a science method class or after the class to clarify the accuracy of the explanation. Although the concept may not be fully understood at the end of three hours, any questions that were raised can be explored later, which could involve discussions in the method class.

Creating a digital explanation such as a slowmation also helps preservice teachers to develop digital literacy skills. For example in constructing the slowmation, the preservice teachers interpreted information from Wikipedia and watched YouTube clips, used a storyboard to plan a sequence, and then took digital still photos that were integrated with other modes in the final digital representation. Whilst there are many tasks or forms of representations that support preservice teachers' learning in methods courses such as writing summaries, drawing sketches and constructing tables and graphs, many do not involve the manipulation of digital modes of communication or the development of digital literacies through the use of one's own personal technology tools. More particularly, developing a slowmation involves making decisions about how to effectively use the technology to 
integrate different modes to achieve 'modal coherence' (Jewitt, 2014) and explain the concept.

Gauging validity or credibility of Internet sources is part of digital literacy and thus, making a slowmation as a teaching resource provides an important opportunity for discussing truth claims and validity concerns regarding information sources. The slowmation process also provides opportunities for preservice teachers to articulate their prior conceptions including reasoning about alternate conceptions. They need such opportunities in order to develop more robust understandings (Taber \& Tan, 2011), otherwise there is a possibility that alternative conceptions may be passed on to school children. This may in part account for the resiliency of some alternate conceptions in the wider population. Phases of the moon is a complex topic with well-documented alternate conceptions. Exposing preservice teachers' alternate science conceptions is thus an important part of their science content learning, and while these alternate conceptions may be highly resilient, if they are not challenged during teacher education, when will they be challenged?

An important implication from this study is that instructors of science methods courses need to be aware of the relationship between expert-created representations and student-created representations and the importance of fostering discussion to negotiate meaning. As argued by Tytler et al. (2013), the use of student-created representations is important in enabling preservice teachers to articulate and justify their ideas. However, as we have shown, student-created representations such as Eliza's sketches shown in Figure 1 may reinforce alternative conceptions. It is therefore important for instructors to introduce scientifically correct expert-created representations in context with students' discussions about their own representations. In essence there needs to be interplay between preservice teachers' articulating and justifying their conceptions through creating representations and expert-generated representations that are introduced at appropriate times to scaffold understanding that builds scientific knowledge in a coherent way and possibly, resolve alternative conceptions. In short, this study shows the importance and relationship of different types of multimodal representations whether created by experts or preservice teachers.

We acknowledge that a limitation of this study is that it only involved three preservice teachers, all with basic science background who volunteered for the study. They also ran out of time in the research period and thus the final product is rough in terms of production quality and quality of the digital explanation. Compared to when preservice teachers create a slowmation as an assessment task in the science methods course, the research time was constrained in ways that slowmation as a task in science methods class is not. We also note a limitation of our data gathering strategy using interviews to probe content knowledge: we cannot assume that because a scientific element was not mentioned, that the participant had no understanding. Conversely, mentioning an element does not necessarily reveal depth or accuracy of understanding. However, our in-process method of recording conversations and gathering artifacts along with analysis of scientific elements showed the process of learning through making a digital teaching resource. This detail for the meaning making process has not been previously articulated.

We believe that the research area of student-generated representations, such as slowmation, will increase as new personal technologies and Web 2.0 and 3.0 capabilities develop. For example some preservice teachers can access the Internet, take digital still photos and make a narrated animation all on a hand-held mobile phone as well as upload the digital product to an Internet site for public viewing and possible peer review. As science educators, we need teaching strategies that encourage our preservice teachers to use their dispositions for and access to personal technologies for the purpose of learning science and within the short time frame of a three-hour class. In short, as preservice teachers increasingly 
use their own technologies for social networking, they should also be encouraged to use them for constructing multiple science representations to make digital teaching resources.

Everyday technology can therefore be used to not only create digital products, but also to display them whereby the discussion of both scientific and alternative conceptions can be encouraged and scaffolded. Opportunities for technology-enhanced teaching and learning will only increase in the $21^{\text {st }}$ century. 


\section{References}

Al-Balushi, S. M. (2013). The effect of different textual narratives on students' explanations at the sub-microscopic level in chemisty. Eurasia Journal of Mathematics, Science and Technology Education, 9(1), 3-10.

Atwood, R. K., \& Atwood, V. A. (1997). Effects of instruction on preservice elementary teachers' conceptions of the causes of night and day and the seasons. Journal of Science Teacher Education, 8, 1-3.

Babai, R., Sekal, R., \& Stavy, R. (2010). Persistence of the intuitive conception of living things in adolescence. Journal of Science Education and Technology, 19, 20-26.

Bell, R. L., \& Trundle, K. C. (2008). The use of computer simulation to promote scientific conceptions of moon phases. Journal of Research in Science Teaching, 45, 346-372.

Bryce, T. G. K., \& Blown, E. J. (2012). The novice-expert continuum in astronomy knowledge. International Journal of Science Education, 34(4), 545-587.

Callison, P. L., \& Wright, E. L. (1993, April). The effect of teaching strategies using models on preservice elementary teachers' conceptions about earth-sun-moon relationships. Paper presented at the annual meeting of the National Association for Research in Science Teaching. Atlanta, GA.

Chi, M. T. H., Bassok, M., Lewis, M., Reimann, P., \& Glasser, R. (1989). Self-explanations: How students study and use examples in learning to solve problems. Cognitive Science, 13, 145-182.

Chi, M., De Leeuw, N., \& Chiu, M. (1994). Eliciting self-explanations improves understanding. Cognitive Science, 18, 439-477.

Cobb, P. (1994). Constructivism in mathematics and science education. Educational Researcher, 23(7), 4-13.

Cobern, W. (1996). Worldview theory and conceptual change in science education. Science Education, 80, 579-610.

Davis, E. A., Petish, D., \& Smithey, J. (2006). Challenges new science teachers face. Review of Educational Research, 76, 607-651.

Driver, R. (1983). The pupil as scientist? Milton Keynes, UK: Open University.

Driver, R., \& Erickson, G. (1983). Theories-in-action: some theoretical and empirical issues in the study of students' conceptual frameworks in science. Studies in Science Education, 10, 37-60.

Fanetti, T. M. (2001). The relationships of scale concepts on college age students' misconceptions about the cause of lunar phases. Unpublished Master's Thesis, Iowa State University, Ames, IA.

Fiorella, L., \& Mayer, R. E. (2014). Role of expectations and explanations in learning by teaching. Contemporary Educational Psychology, 39(2), 75-85.

Gilbert, J. K. (2007). Visualization in science education. Dordrecht: Springer.

Gilbert, J. K., \& Watts, D. M. (1983). Concepts, misconceptions and alternative conceptions: Changing perspectives in science education. Studies in Science Education, 10, 61-98.

Haim, E. (2010). Using photographs to probe students' understanding of physical concepts: the case of Newton's $3^{\text {rd }}$ Law. Research in Science Education, 40(4), 589-603.

Hand, B., \& Choi, A. (2010). Examining the impact of student use of multiple modal representations in constructing arguments in organic chemistry laboratory classes. Research in Science Education, 40, 29-44.

Hegarty, M. (2014). Spatial thinking in undergraduate science education. Spatial Cognition and Computation, 14(2), 142-167.

Hewson, P., \& Hewson, M. (1984). The role of conceptual conflict in conceptual change and the design of science instruction. Instructional Science, 13, 1-13.

Hiller, J. H., Deichman, J. W., \& Pirkle, J. K. (1975). Expectancy to teach: Possible incentive 
for learning. Journal of Experimental Education, 42(1), 37-39.

Hoban, G. (2005). From claymation to slowmation: A teaching procedure to develop students' science understandings. Teaching Science: Australian Science Teachers' Journal, 51(2), 26-30.

Hoban, G. (2007). Using slowmation to engage preservice elementary teachers in understanding science content knowledge. Contemporary Issues in Technology and Teacher Education, 7(2), 1-9.

Hoban, G. (2009). Facilitating learner-generated animations with slowmation. In L. Lockyer, S. Bennett, S. Agostino \& B. Harper (Eds.), Handbook of Research on Learning Design and Learning Objects: Issues, Applications, and Technologies (pp. 313-330). Hershey, PA: IGI Global.

Hoban, G., \& Nielsen, W. (2010). The 5 R's: A new teaching approach to encourage student generated animations (Slowmations) of science concepts. Teaching Science: Australian Science Teachers' Journal, 56(3), 33-38.

Hoban, G., Loughran, J., \& Nielsen, W. S. (2011). Slowmation: Engaging preservice elementary teachers with science knowledge through creating digital animations. Journal of Research in Science Teaching, 48(9), 985-1009.

Hoban, G., \& Nielsen, W. (2012). Learning science through designing and making a narrated stop-motion animation: A case study of preservice teachers conceptual change with slowmation. International Journal of Science Education, 35(1), 119-146. doi: 10.1080/09500693.2012.670286

Hoban, G., \& Nielsen, W. (2014). Creating a narrated stop-motion animation to explain science: The affordances of "slowmation" for generating discussion. Teaching and Teacher Education, 42, 68-78.

Hoban, G., Nielsen, W., \& Shepherd, A. (2013). Explaining and communicating science using student-created blended media. Teaching Science: Australian Science Teachers' Journal, 59(1), 32-35.

Howes, E. V. (2002). Learning to teach Science for All in the elementary grades: What do preservice teachers bring? Journal of Research in Science Teaching, 39, 845-869.

Hubber, P., Tytler, R., \& Haslam, F. (2010). Teaching and learning about force with a representational focus: Pedagogy and teacher change. Research in Science Education, 40, 5-28.

Jewitt, K. (2014) (Ed.). Routledge Handbook of Multimodal Analysis. London: Routledge.

Johnson, P., \& Gott, R. (1996). Constructivism and evidence from children's ideas. Science Education, 80, 561-577.

Jonassen, D., Myers, J. M., \& McKillop, A. M. (1996). From constructivism to constructionism: Learning with hypermedia/multimedia rather than from it. In B. G. Wilson (Ed.), Constructivist learning environments (pp. 93-106). Engelwood Cliffs, NJ: Educational Technology Publications.

Kozma, R. B. (2003). The material features of multiple representations and their cognitive and social affordances for science understanding. Learning and Instruction, 35, 205226.

Kress, G. (2010). Multimodality: A social semiotic approach to contemporary communication. London: Routledge.

Lelliott, A., \& Rollnick, M. (2010). Big ideas: A review of astronomy education research 1974-2008. International Journal of Science Education, 32(13), 1771-1799.

Lemke, J. (1998). Multiplying meaning: Visual and verbal semiotics in scientific text. In J. R. Martin \& R. Veel (Eds.), Reading science: Critical and functional perspectives on discourses of science (pp. 87-113). New York, NY: Routledge. 
Lombrozo, T. (2012). Explanation and abductive inference. In K. J. Holyoak \& G. R. Morrison (Eds.), Handbook of thinking and reasoning (pp. 260-276). Oxford, England: Oxford University.

Merriam, S. (1998). Qualitative research and case study applications in education. San Francisco: Jossey Bass.

Mintzees, J. L., Wandersee, J. H., \& Novak, J. D. (1998). Teaching for understanding: A human constructivist view. San Diego, CA: Academic.

National Research Council. (2012). Education for life and work. Washington, DC: National Academies.

Nestojko, J. F., Bui, D. C., Kornell, N., \& Bjork, E. L. (2014). Expecting to teach enhances learning and organization of knowledge in free recall of text passages. Memory \& Cognition, 42, 1038-1048.

New South Wales Board of Studies. (2012). Science K-10 syllabus: Science and technology K-6. Sydney, NSW: State of New South Wales.

Ogan-Bekiroglou, F. (2007). Effects of model-based teaching on preservice teachers' conceptions of the moon, moon phases and other lunar phenomena. International Journal of Science Education, 29(5), 555-593.

Peirce, C. (1931/1955). Logic as semiotic: The theory of signs. In B. Justus (Ed.), Philosophical writings of Peirce (1893-1910) (pp. 98-119). New York, NY: Dover.

Phillips, L., Norris, S., \& Macnab, J. (2010). Visualization in mathematics, reading and science education. Dordrecht: Springer.

Prain, V., \& Tytler, R. (2012). Learning through constructing representations in science: A framework of representational affordances. International Journal of Science Education, 34, 2751-2773.

Prain, V., \& Waldrip, B. (2006). An exploratory study of teachers' and students' use of multimodal representations of concepts in primary science. International Journal of Science Education, 28, 1843-1866.

Renkl, A. (1995). Learning for later teaching: An exploration of meditational links between teaching expectancy and learning results. Learning and Instruction, 5(1), 21-36.

Russell, J., \& Kozma, R. (2007). Assessing learning from the use of multimedia chemical visualizations. In J. K. Gilbert (Ed.), Visualization in science education (pp. 299332). Dordrecht: Springer.

Sadler, P. M., Gould, R., Brecher, K., \& Hoffman, B. (2000). Astronomical experiences using internet-accessible remote instrumentation. In M. J. Jacobson (Ed.), Innovations in science and mathematics education: Advanced designs for technologies and learning (pp. 287-320). Mahwah, NJ: Lawrence Erlbaum Associates.

Sequira, M., \& Leite, L. (1991). Alternate conceptions and history of science in physics teacher education. Science Education, 75, 45-56.

Stake, R. (1995). The art of case study research. Thousand Oaks, CA: Sage.

Taber, K. S., \& Tan, K. C. D. (2011). The insidious nature of 'hard-core' alternative conceptions: Implications for the constructivist research programme of patterns in high school students' and pre-service teachers' thinking about ionisation energy. International Journal of Science Education, 33, 259-297.

Tang, K. S., Delgado, C., \& Moje, E. B. (2014). An integrative framework for the analysis of multiple and multimodal representations for meaning-making in science education. Science Education, 98(2), 305-326.

Trumper, R., Raviolo, A., \& Shnersch, A. (2000). A cross-cultural survey of conceptions of energy among elementary school teachers in training: Empirical results from Israel and Argentina. Teaching and Teacher Education, 16, 697-714. 
Trundle, K., Atwood, R. K., \& Christopher, J. (2002). Preservice elementary teachers' conceptions of moon phases before and after instruction. Journal of Research in Science Teaching, 39, 633-658.

Trundle, K., Atwood, R. K., \& Christopher, J. (2007). A longitudinal study of conceptual change: Preservice elementary teachers' conceptions of moon phases. Journal of Research in Science Teaching, 44, 303-326.

Tytler, R. (1998). Children's conceptions of air pressure: Exploring the nature of conceptual change. International Journal of Science Education, 20, 929-958.

Tytler, R. (2008). Re-imagining science education. Melbourne, VIC: ACER.

Tytler, R., \& Prain, V. (2010). A framework for re-thinking learning in science from recent cognitive perspectives. International Journal of Science Education, 32, 2055-2078.

Tytler, R., Prain, V., Hubber, P., \& Waldrip, B. (Eds.) (2013). Constructing representations to learn science. The Netherlands: Sense Publishers.

White, R., \& Gunstone, R. (1989). Metalearning and conceptual change: Special issue. International Journal of Science Education, 11, 577-566.

White, R., \& Gunstone, R. (1992). Probing understanding. London: Falmer.

Yin, R. (2003). Case study research: Design and methods. Thousand Oaks, CA: Sage.

Yore, L., \& Hand, B. (2010). Epilogue: Plotting a research agenda for multiple representations, multiple modality, and multimodal representational competency. Research in Science Education, 40, 93-101.

\section{Acknowledgement}

We would like to thank the three preservice teachers who volunteered for this research and the anonymous reviewers who offered constructive feedback in shaping this paper. We also thank the University of Wollongong for financial support for this research. 